\title{
PATTERN OF XYLEM PHENOLOGY IN CONIFERS OF COLD ECOSYSTEMS AT
}

THE NORTHERN HEMISPHERE

Running head: xylem phenology across cold forest ecosystems

Sergio Rossi ${ }^{1,2,3}$, Tommaso Anfodillo ${ }^{4}$, Katarina Čufar ${ }^{5}$, Henri E. Cuny ${ }^{6}$, Annie

Deslauriers $^{1}$, Patrick Fonti ${ }^{7}$, David Frank ${ }^{7,8}$, Jožica Gričar ${ }^{10}$, Andreas Gruber ${ }^{11}$, Jian-

Guo Huang ${ }^{2,3 *}$, Tuula Jyske ${ }^{12}$, Jakub Kašpar ${ }^{13}$, Gregory King ${ }^{7,8,9}$, Cornelia Krause ${ }^{1}$, Eryuan Liang ${ }^{14}$, Harri Mäkinen ${ }^{12}$, Hubert Morin'1, Pekka Nöjd ${ }^{12}$, Walter Oberhuber11, Peter Prislan ${ }^{10}$, Cyrille B.K. Rathgeber ${ }^{6}$, Antonio Saracino ${ }^{15}$, Irene Swidrak ${ }^{11}$, Václav Treml $^{13}$

${ }^{1}$ Département des Sciences Fondamentales, Université du Québec à Chicoutimi, Chicoutimi (QC), Canada

${ }^{2}$ Key Laboratory of Vegetation Restoration and Management of Degraded Ecosystems, South China Botanical Garden, Chinese Academy of Sciences, Guangzhou, China

${ }^{3}$ Provincial Key Laboratory of Applied Botany, South China Botanical Garden, Chinese Academy of Sciences, Guangzhou, China

${ }^{4}$ Dipartimento Territorio e Sistemi Agro-Forestali, Università degli Studi di Padova, Legnaro (PD) Italy

${ }^{5}$ University of Ljubljana, Biotechnical Faculty, Ljubljana, Slovenia

${ }^{6}$ LERFoB, INRA, AgroParisTech, F-54000, Nancy, France

${ }^{7}$ Swiss Federal Research Institute WSL, Birmensdorf, Switzerland 
${ }^{13}$ Department of Physical Geography and Geoecology, Charles University in Prague, Prague,

27 Czech Republic

${ }^{14}$ Key Laboratory of Alpine Ecology and Biodiversity, Key Laboratory of Tibetan Environment Changes and Land Surface Processes, Institute of Tibetan Plateau Research, Chinese Academy of Sciences, Beijing, China

* Corresponding author: Jian-Guo Huang, Key Laboratory of Vegetation Restoration and Management of Degraded Ecosystems, South China Botanical Garden, Chinese Academy of huangjg@scbg.ac.cn.

Keywords: Cambium, cell differentiation, cell production, climate change, conifers, growth, meristem, secondary wall formation 
The interaction between xylem phenology and climate assesses forest growth and productivity and carbon storage across biomes under changing environmental conditions. We tested the hypothesis that patterns of wood formation are maintained unaltered despite the temperature changes across cold ecosystems. Wood microcores were collected weekly or biweekly throughout the growing season for periods varying between 1-13 years during 1998-2014 and cut in transverse sections for assessing the onset and ending of the phases of xylem differentiation. The dataset represented 1321 trees belonging to 10 conifer species from 39 sites in the Northern hemisphere and covering an interval of mean annual temperature exceeding $14 \mathrm{~K}$. The phenological events and mean annual temperature of the sites were related linearly, with spring and autumnal events being separated by constant intervals across the range of temperature analysed. At increasing temperature, first enlarging, wall-thickening and mature tracheids appeared earlier, and last enlarging and wall-thickening tracheids occurred later. Overall, the period of wood formation lengthened linearly with the mean annual temperature, from 83.7 days at $-2{ }^{\circ} \mathrm{C}$ to 178.1 days at $12{ }^{\circ} \mathrm{C}$, at a rate of 6.5 days ${ }^{\circ} \mathrm{C}^{-1}$. April-May temperatures produced the best models predicting the dates of wood formation.

Our findings demonstrated the uniformity of the process of wood formation and the importance of the environmental conditions occurring at the time of growth resumption. Under warming scenarios, the period of wood formation might lengthen synchronously in the cold biomes of the Northern hemisphere. 
Perennial plants synchronize their physiological processes with local climate according to a trade-off between maximization of resource acquisition and damage avoidance due to harsh environmental conditions (Chuine, 2010, Nord \& Lynch, 2009). In temperate and cold ecosystems of the Northern hemisphere, the cyclical reactivation and termination of the physiological activity of meristems has a distinct annual pattern that is described by the phenology of buds, flowers and cambium (Delpierre et al., 2015). Their activity is mainly concentrated in a well-defined period of time between spring and autumn, when temperatures are favourable for growth and reproduction, while it stops or slows down during winter.

Phenology is a dynamic and sensitive biological process that has been demonstrated to vary at both short and long time scales according to the current weather (Gruber et al., 2010, Swidrak et al., 2011) and increasing temperatures (Chmielewski \& Rötzer, 2001, Menzel et al., 2006). The phenological events change according to the clinal variation of environmental factors, with the growing season shortening at higher latitudes and altitudes (Jyske et al., 2014, Moser et al., 2010). Despite the species-specific variations and ecotypic adaptations to local conditions, latitudinal and altitudinal patterns in phenology may also be found across biomes. However, at hemispheric scale, the mere geographical location becomes meaningless because the effects of water bodies and changes in elevation on mesoclimatic conditions can modify the predictable relationships between geographical coordinates and timing of growth. Accordingly, Rossi et al. (2011) showed that the milder thermal conditions close to big lakes or the lower temperatures experienced by trees of high altitudes affected xylem phenology irrespective of the latitude of the sites. Temperature is one of the main driving forces for plant growth in terrestrial ecosystems, and interacts with photoperiod in defining the timings of growth resumption (Körner \& Basler, 2010). Temperature-based models should therefore be 
able to provide more intrinsic growth predictions than the models based on latitude or altitude, which merely describe a geographical variation invariable over time.

Wood in trees consists of the xylem cells produced by the cambium in order to build the hydraulic transport system, store substances and ensure mechanical support. Cambial cells divide repeatedly and generate cell derivatives that differentiate physiologically and morphologically until final maturity (Rossi et al., 2012). The process of wood formation, or xylogenesis, lasts from a few weeks to several months, according to species and individual growth rate, and, more specifically, to climate (Rathgeber et al., 2011, Schmitt et al., 2004, Treml et al., 2015, Vieira et al., 2015). This wide variation in wood formation demonstrates the high plasticity of trees in adapting their growth processes to local environmental conditions.

Trees capture atmospheric carbon dioxide and convert it to structural carbohydrates while building new cells. Wood formation is one of the strongest carbon sinks in trees, making xylogenesis a major process of long-term carbon sequestration and accumulation in terrestrial systems. During the growing season, the outermost wood is composed of a pool of differentiating and mature cells that are interconnected by a sequence of fixed events (Delpierre et al., 2015, Rossi et al., 2012). At mid and high latitudes and altitudes, the annual amount of wood production is determined by the growth rate and length of the period favourable for cell division and maturation (Cuny et al., 2012, Rathgeber et al., 2011, Rossi et al., 2014). Although rate and duration of wood formation change with tree species, identifying the timings and climatic conditions driving wood formation is an essential step in understanding the dynamics of tree growth and forest productivity at a hemispheric scale. 
107 An extensive dataset from 1321 trees belonging to 10 species was compiled containing intra-

108 annual data on wood formation and temperature collected by the authors in 39 plots with

109 similar methods during 1998-2014. The dataset was collected from temperate to northern

110 boreal sites on three continents, ranging from Southern Italy to Northern Finland and Canada,

111 from low altitudes in France and Slovenia to high ones on the Alps, Bohemian Massif in the

112 Czech Republic and Tibetan Plateau in China (Fig. S1). The sites represented temperate to

113 boreal forests, and treeline ecotones, including the highest treeline of the North hemisphere on

114 the Tibetan Plateau. The aim of the study was to compare wood formation over broad

115 geographical scale by testing the hypothesis that the timings of xylem phenology in conifers

116 change according to the variation of the temperature of the sites across temperate and boreal

117 forest ecosystems. 


\section{Site selection and sampling}

The air temperature and xylem phenology data were collected in 39 sites located at different altitudes and latitudes of nine countries in North-America, Europe and Asia (Table 1). The sites consisted of permanent plots representing temperate-cold to boreal conifer stands. In each site, from one to 24 adult trees with upright and injury-free stems were selected for sampling. Trees with polycormic stems, partially dead crowns, reaction wood or evident damage were avoided. In each site, 1-3 coniferous species were monitored, for a total of ten species for the whole study.

The trees were monitored during 1998-2014, the number of years ranging from one to 13 per site, throughout the growing season from March-April to October-December, according to the climatic conditions of the sites (Table 1). Wood microcores were collected weekly, or occasionally biweekly, at breast height $(1.3 \pm 0.3 \mathrm{~m})$ on the stem using surgical bone sampling needles or a Trephor (Rossi et al., 2006a). The samples contained mature and developing xylem of the current year, the cambial zone and adjacent phloem, and at least one previous complete tree ring. The microcores were stored in solutions of propionic or acetic acid mixed with formaldehyde or ethanol at $5{ }^{\circ} \mathrm{C}$.

The microcores were dehydrated with successive immersions in ethanol and D-limonene, and embedded in paraffin or glycol methacrylate, with the exception of samples from Switzerland, which were not embedded. The microcores were cut with rotary or sledge microtomes in transverse sections of 10-30 $\mu$ m thick (Gruber et al., 2010, Moser et al., 2010, Rossi et al., 2006a). The sections were simple-stained with cresyl violet acetate or double-stained with 
141 safranin and astrablue, and examined under bright-field and polarized light (Moser et al., 142 2010, Rossi et al., 2006b).

143 Table 1: Sites, species and years included in the analysis. The name of each site is associated 144 with the country reported in the form of the alpha- 2 code according to the International

145 Organization for Standardization (ISO 3166). Species are reported with the following 146 acronyms: ABAL, Abies alba; ABBA, Abies balsamea; ABGE, Abies georgei; LADE, Larix 147 decidua; PCAB, Picea abies; PCMA, Picea mariana; PICE, Pinus cembra; PILE, Pinus leucodermis; PISY, Pinus sylvestris; PIUN, Pinus uncinata.

\begin{tabular}{|c|c|c|c|c|c|c|c|}
\hline \multirow[b]{2}{*}{ ID } & \multirow[b]{2}{*}{ Site } & \multirow[b]{2}{*}{ Latitude } & \multirow[b]{2}{*}{ Longitude } & \multicolumn{3}{|l|}{ Altitude } & \multirow{2}{*}{$\begin{array}{l}\text { Number } \\
\text { of trees }\end{array}$} \\
\hline & & & & (m a.s.1.) & Study years & Species & \\
\hline SYG & CN-Sygera Mountain & $29^{\circ} 39^{\prime} \mathrm{N}$ & $94^{\circ} 42^{\prime} \mathrm{E}$ & 3850 & $2007-2009$ & ABGE & 5 \\
\hline POL & IT-Pollino & $39^{\circ} 54^{\prime} \mathrm{N}$ & $16^{\circ} 12^{\prime} \mathrm{E}$ & 2053 & 2003-2004 & PILE & 10 \\
\hline SUS & IT-Val di Susa & $45^{\circ} 3^{\prime} \mathrm{N}$ & $6^{\circ} 40^{\prime} \mathrm{E}$ & 2030 & 2003-2004 & LADE, PICE, PIUN & 15 \\
\hline PAN & SI-Panska reka & $46^{\circ} 0 \mathrm{~N}$ & $14^{\circ} 40^{\prime} \mathrm{E}$ & 400 & 2009-2012 & PCAB & 6 \\
\hline MEN & SI-Menina Planina & $46^{\circ} 16^{\prime} \mathrm{N}$ & $14^{\circ} 48^{\prime} \mathrm{E}$ & 1200 & 2009-2012 & PCAB & $6-8$ \\
\hline $\mathrm{N} 22$ & CH-Lötschental-N22 & $46^{\circ} 22^{\prime} \mathrm{N}$ & $7^{\circ} 46^{\prime} \mathrm{E}$ & 2150 & $2007-2008$ & LADE & 4 \\
\hline N08 & CH-Lötschental-N08 & $46^{\circ} 23^{\prime} \mathrm{N}$ & $7^{\circ} 45^{\prime} \mathrm{E}$ & 800 & 2008 & LADE, PCAB & 8 \\
\hline N16 & CH-Lötschental-N16 & $46^{\circ} 23^{\prime} \mathrm{N}$ & $7^{\circ} 45^{\prime} \mathrm{E}$ & 1300 & $2007-2008$ & LADE, PCAB & 8 \\
\hline N13 & CH-Lötschental-N13 & $46^{\circ} 23^{\prime} \mathrm{N}$ & $7^{\circ} 45^{\prime} \mathrm{E}$ & 1350 & $2007-2008$ & LADE, PCAB & 8 \\
\hline N19 & CH-Lötschental-N19 & $46^{\circ} 23^{\prime} \mathrm{N}$ & $7^{\circ} 46^{\prime} \mathrm{E}$ & 1900 & $2007-2008$ & LADE, PCAB & 8 \\
\hline S16 & CH-Lötschental-S16 & $46^{\circ} 24^{\prime} \mathrm{N}$ & $7^{\circ} 45^{\prime} \mathrm{E}$ & 1300 & $2007-2008$ & LADE, PCAB & 8 \\
\hline S19 & CH-Lötschental-S19 & $46^{\circ} 24^{\prime} \mathrm{N}$ & $7^{\circ} 45^{\prime} \mathrm{E}$ & 1900 & $2007-2008$ & LADE, PCAB & 8 \\
\hline S22 & CH-Lötschental-S22 & $46^{\circ} 24^{\prime} \mathrm{N}$ & $7^{\circ} 44^{\prime} \mathrm{E}$ & 2150 & $2007-2008$ & LADE & 4 \\
\hline SVT & IT-San Vito di Cadore & $46^{\circ} 26^{\prime} \mathrm{N}$ & $12^{\circ} 13^{\prime} \mathrm{E}$ & 1000 & 2003 & PCAB & 1 \\
\hline $5 \mathrm{~T} 1$ & IT-Cinque Torri 1 & $46^{\circ} 27^{\prime} \mathrm{N}$ & $12^{\circ} 8^{\prime} \mathrm{E}$ & 2085 & $2001-2005$ & LADE, PCAB, PICE & 15 \\
\hline $5 \mathrm{~T} 3$ & IT-Cinque Torri 3 & $46^{\circ} 27^{\prime} \mathrm{N}$ & $12^{\circ} 8^{\prime} \mathrm{E}$ & 2085 & 2004-2005 & LADE, PCAB, PICE & 15 \\
\hline $5 \mathrm{~T} 2$ & IT-Cinque Torri 2 & $46^{\circ} 28^{\prime} \mathrm{N}$ & $12^{\circ} 8^{\prime} \mathrm{E}$ & 2156 & $2002-2005$ & LADE, PCAB, PICE & 11 \\
\hline
\end{tabular}




\begin{tabular}{|c|c|c|c|c|c|c|c|}
\hline & & & & Altitude & & & Number \\
\hline ID & Site & Latitude & Longitude & (m a.s.1.) & Study years & Species & of trees \\
\hline TIM & AT-Patscherkofel-timberline & $47^{\circ} 12^{\prime} \mathrm{N}$ & $11^{\circ} 27^{\prime} \mathrm{E}$ & 1950 & 2007 & PICE & 6 \\
\hline TRE & AT-Patscherkofel-treeline & $47^{\circ} 12^{\prime} \mathrm{N}$ & $11^{\circ} 27^{\prime} \mathrm{E}$ & 2110 & 2007 & PICE & 6 \\
\hline $\mathrm{KRU}$ & AT-Patscherkofel-krummholz & $47^{\circ} 12^{\prime} \mathrm{N}$ & $11^{\circ} 27^{\prime} \mathrm{E}$ & 2180 & 2007 & PICE & 5 \\
\hline DRY & AT-Tschirgant dry-mesic & $47^{\circ} 14^{\prime} \mathrm{N}$ & $10^{\circ} 50^{\prime} \mathrm{E}$ & 750 & $2007-2012$ & LADE, PCAB, PISY & $5-24$ \\
\hline SIM & CA-Simoncouche & $48^{\circ} 13^{\prime} \mathrm{N}$ & $71^{\circ} 15^{\prime} \mathrm{W}$ & 338 & $2002-2014$ & ABBA, PCMA & $5-20$ \\
\hline ABR & FR-Abreschviller & $48^{\circ} 21^{\prime} \mathrm{N}$ & $7^{\circ} 4^{\prime} \mathrm{E}$ & 430 & 2007-2009 & ABAL, PCAB, PISY & $13-14$ \\
\hline WAL & FR-Walscheid & $48^{\circ} 22^{\prime} \mathrm{N}$ & $7^{\circ} 5^{\prime} \mathrm{E}$ & 370 & $2007-2009$ & ABAL, PCAB, PISY & $14-15$ \\
\hline ARV & CA-Arvida & $48^{\circ} 26^{\prime} \mathrm{N}$ & $71^{\circ} 9^{\prime} \mathrm{W}$ & 80 & $1999-2000$ & ABBA & 18 \\
\hline GRD & FR-Grandfontaine & $48^{\circ} 29^{\prime} \mathrm{N}$ & $7^{\circ} 9^{\prime} \mathrm{E}$ & 643 & $2007-2009$ & ABAL, PCAB, PISY & 15 \\
\hline AMN & FR-Amance & $48^{\circ} 44^{\prime} \mathrm{N}$ & $6^{\circ} 19^{\prime} \mathrm{E}$ & 270 & $2006-2007$ & ABAL & $15-20$ \\
\hline BER & CA-Bernatchez & $48^{\circ} 51^{\prime} \mathrm{N}$ & $70^{\circ} 20^{\prime} \mathrm{W}$ & 611 & $2002-2014$ & PCMA & $5-10$ \\
\hline MIS & CA-Mistassibi & $49^{\circ} 43^{\prime} \mathrm{N}$ & $71^{\circ} 56^{\prime} \mathrm{W}$ & 342 & $2002-2014$ & PCMA & $5-10$ \\
\hline L23 & CA-Liberal 23 & $49^{\circ} 58^{\prime} \mathrm{N}$ & $72^{\circ} 30^{\prime} \mathrm{W}$ & 380 & $1998-2000$ & $\mathrm{ABBA}$ & 10 \\
\hline L24 & CA-Liberal 24 & $49^{\circ} 58^{\prime} \mathrm{N}$ & $72^{\circ} 30^{\prime} \mathrm{W}$ & 430 & 1998-2001 & ABBA & $5-10$ \\
\hline DAN & CA-Camp Daniel & $50^{\circ} 41^{\prime} \mathrm{N}$ & $72^{\circ} 11^{\prime} \mathrm{W}$ & 487 & $2002-2014$ & PCMA & $5-10$ \\
\hline LH1 & CZ-Lucní Hora-timberline & $50^{\circ} 42^{\prime} \mathrm{N}$ & $15^{\circ} 39^{\prime} \mathrm{E}$ & 1310 & 2010-2012 & PCAB & $6-10$ \\
\hline LH2 & CZ-Lucní Hora-treeline & $50^{\circ} 43^{\prime} \mathrm{N}$ & $15^{\circ} 40^{\prime} \mathrm{E}$ & 1450 & 2010-2012 & PCAB & $6-9$ \\
\hline MIR & CA-Mirage & $53^{\circ} 47^{\prime} \mathrm{N}$ & $72^{\circ} 52^{\prime} \mathrm{W}$ & 384 & $2012-2013$ & PCMA & 10 \\
\hline RUO & FI-Ruotsinkylä & $60^{\circ} 12^{\prime} \mathrm{N}$ & $25^{\circ} 0^{\prime} \mathrm{E}$ & 60 & $2008-2010$ & PCAB, PISY & $8-10$ \\
\hline HYY & FI-Hyytiälä & $61^{\circ} 53{ }^{\prime} \mathrm{N}$ & $24^{\circ} 18^{\prime} \mathrm{E}$ & 181 & 2008 & PCAB, PISY & 6 \\
\hline KIV & FI-Kivalo & $66^{\circ} 12^{\prime} \mathrm{N}$ & $26^{\circ} 23^{\prime} \mathrm{E}$ & 140 & 2009 & PCAB & 5 \\
\hline VAR & FI-Värriö & $67^{\circ} 30^{\prime} \mathrm{N}$ & $29^{\circ} 23^{\prime} \mathrm{E}$ & 390 & 2009 & PISY & 4 \\
\hline
\end{tabular}


151

A common protocol of tracheid classification was followed at all sites in order to obtain comparable data. In each sample, the number of tracheids in the radial enlargement, secondary cell-wall thickening, and mature phases were counted along one to three radial tracheid rows. Enlarging tracheids were composed of a thin primary wall but had a radial diameter at least twice that of a cambial cell (Rossi et al., 2006b). Discrimination between enlarging and wall thickening tracheids was based on birefringence of the secondary cell wall under polarized light (Abe et al., 1997). No birefringence was observed in enlarging tracheids, which lack a secondary wall. Colour changes from violet to blue (simple cresyl violet acetate staining) or from blue to red (double safranin astra-blue staining) indicated the termination of lignification. Absence of cytoplasm and a complete colour change over the whole cell wall marked the end of lignification and tracheid maturity (Gričar et al., 2005).

The mean number of tracheids in each developmental phase at each sampling date was used to assess the onset and ending of the xylem differentiation phases. In spring, when at least one tangential row of tracheids was observed in the enlarging, wall thickening or mature phase, the phase was considered to have begun. In late summer, when no tracheids were observed in a differentiation phase, wood formation was considered complete. Xylem phenology was represented by the dates corresponding to (1) the first enlarging tracheid, (2) first wallthickening tracheid, (3) first mature tracheid, (4) last enlarging tracheid, and (5) last wallthickening tracheid. The timings of xylem phenology, computed as day of the year (DOY), and the total number of tracheids in a radial row produced annually were calculated for each tree, site and year. Tracheid production was assessed by fitting the Gompertz sigmoid curve to the total number of new tracheids produced during the year and estimating the upper asymptote of the function (Deslauriers et al., 2008). Fifty-seven out of 1321 trees $(4.3 \%$ of all 
tree-year combinations) were excluded from the analyses because the function produced no asymptote or the tracheid production was anomalous.

\section{Temperature data}

Temperature data were collected from sensors fixed at 2-3 $\mathrm{m}$ from the soil in shielded weather stations installed in a forest gap beside or close to the sampled trees. Temperature was recorded hourly or sub-hourly by dataloggers, and daily mean, minimum and maximum values were calculated. In Finland, the data from the closest weather station maintained by the Finnish Meteorological Institute were used for each site. The datasets covered the entire year. However, in the case of occasional missing values, temperatures were estimated by using time series available from one or more weather stations located in the proximity of the sites and with similar climatic conditions.

\section{Statistical analyses}

A cluster analysis using the average linkage method was used for assessing the distance between the study sites based on the monthly mean temperatures. The distance between two clusters was the arithmetic mean distance between groups, which were represented by the sites.

A random-effects analysis of variance was performed to isolate the proportion of variation accounted by the factors site, species, tree and year in the studied variables (phenological events and tracheid production). The analysis included the Restricted Maximum Likelihood (REML) method of the NESTED procedure in SAS (SAS Institute Inc., Cary, NC), which allowed to process data with nested (hierarchical) structure originating from an unbalanced design. 
196 The dates of xylem phenology were modelled by Generalized Linear Models (GLM) using the

197 DOY of each event (onset and cessation) as dependent variable, and the mean annual

198 temperature at each site and the five phases of xylem phenology as quantitative and

199 classification variable, respectively. The statistical significance of the differences between the

200 slopes of regressions was tested by orthogonal contrasts. Before and after the fitting, the

201 distributions of the input data and residuals were checked for normality. GLM was performed

202 using the SAS software. The model was also tested with the weekly mean temperatures as

203 independent variables and using a bootstrap procedure with 10,000 replications. Only

204 temperatures occurring before or during the growing period were analysed. 


\section{Temperature across sites}

During the study years, the mean annual temperature across the studied sites ranged by more than $14 \mathrm{~K}$, from $-2.3{ }^{\circ} \mathrm{C}$ in MIR (Canada) to $12.0{ }^{\circ} \mathrm{C}$ in PAN (Slovenia). All sites had a cold winter, with the mean daily temperatures below zero for periods varying between 20 days in France (WAL and AMN) and 180 days in Finland (KIV) and Canada (BER). In three sites, VAR (Finland), DAN (Canada), and MIS (Canada), the mean temperature remained below 0 ${ }^{\circ} \mathrm{C}$ for more than 190 days. The coldest episodes were observed in Canada (DAN and MIR), with absolute minimum temperatures below $-47^{\circ} \mathrm{C}$. The warmest winters occurred in PAN (Slovenia), WAL (France) and N08 (Switzerland), where absolute minimum temperatures reached $-7.6{ }^{\circ} \mathrm{C}$. The absolute maximum temperatures ranged between $19.7{ }^{\circ} \mathrm{C}$ in Austria (KRU) and $37.1^{\circ} \mathrm{C}$ in Slovenia (MEN and PAN).

The sites were grouped in three main clusters based on the monthly mean temperatures extracted from the time series available (Fig. 1). The first cluster included 10 sites from Canada and northern Finland. At these sites, the monthly mean temperatures ranged between 20 and $20^{\circ} \mathrm{C}$, representing continental conditions, with short warm summers and long cold winters. The second cluster was represented by nine sites, with monthly mean temperatures varying between -5 and $20{ }^{\circ} \mathrm{C}$. These were the warmest sites of the dataset, and were located in Central Europe and at the lower Alpine altitudes. The European southern boreal sites and treeline and timberline sites were included in the third cluster, representing 20 sites with a narrower range of monthly mean temperature than those observed in the first cluster. The sites of the third cluster were characterized by low winter temperatures and cool summers (Fig. 1). 


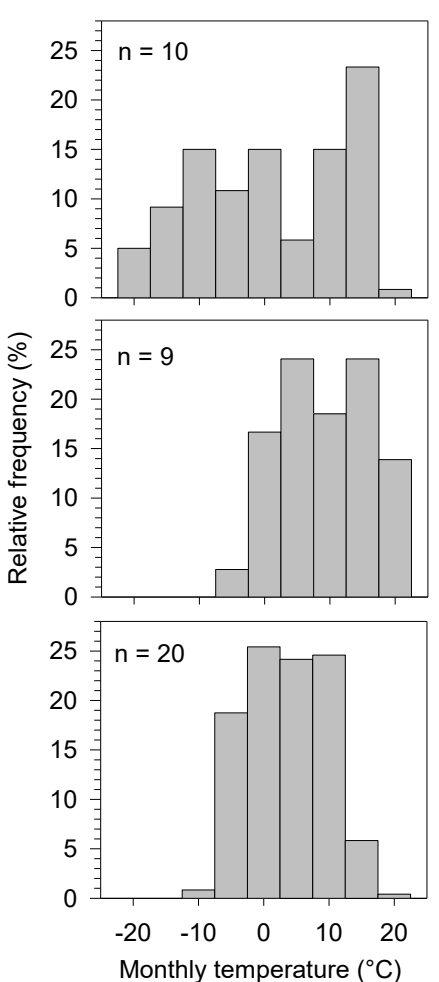

228 three main clusters.

\section{Variance partition}

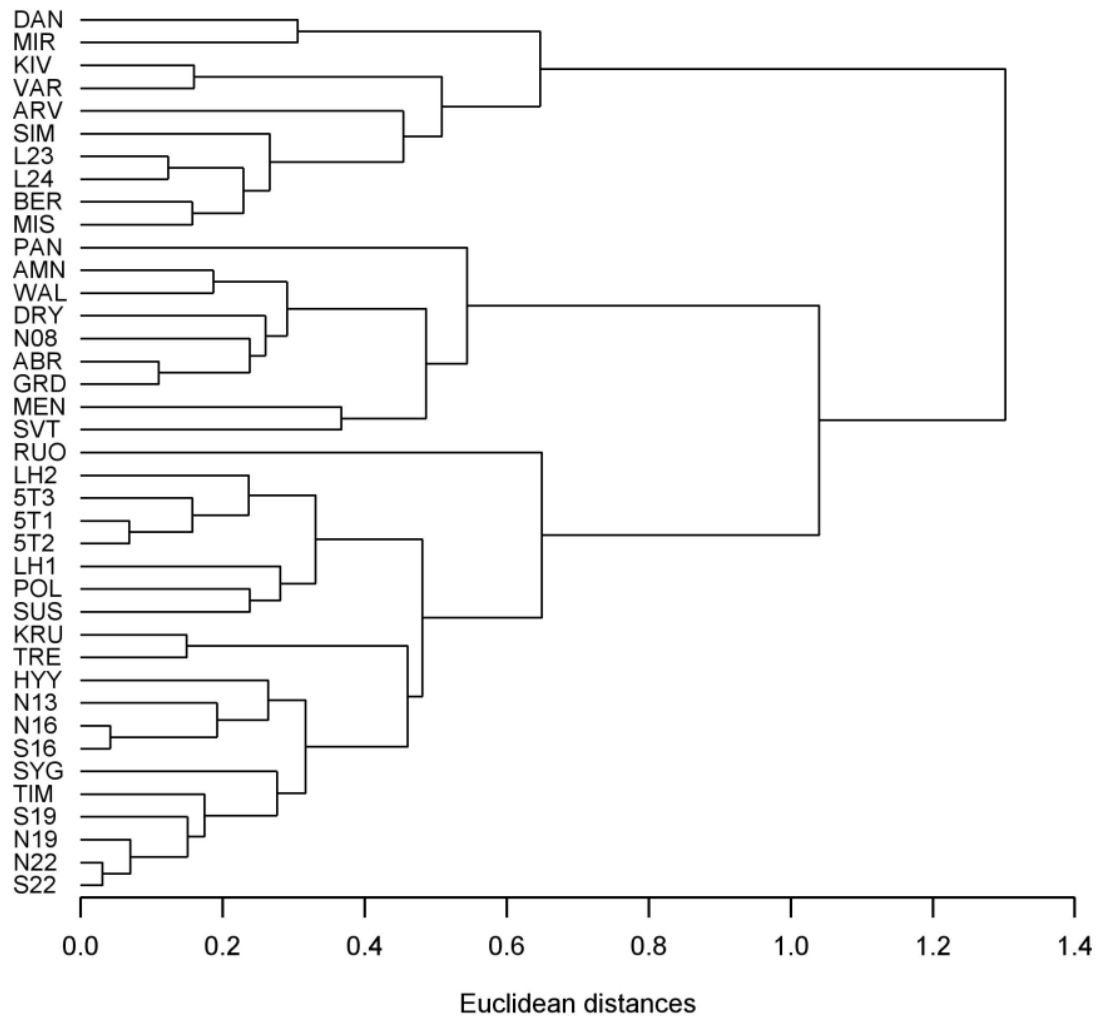

Figure 1: Dendrogram generated by a cluster analysis based on the monthly temperatures of the 39 study sites. The left panel shows the frequency distributions of the temperatures of the

The contribution of site, species, tree and year to the total variance in the five phases of xylem phenology and annual total production of tracheids differed according to two main patterns (Fig. 2). First, the species accounted for a high proportion of variation (40.0-48.2\%) in the variables related to spring events, i.e. the dates of the first enlarging, wall-thickening and mature tracheids. The site explained between 25.0 and $32.9 \%$ of the variance in the spring events, with the lowest percentage $(25.0 \%)$ being estimated for the first enlarging tracheid. In 
the spring events, the percentage of the variance accounted for by the factors tree and year was clearly lower, and ranged between 10.9 and $15.7 \%$ (Fig. 2).

In the phenological events occurring in autumn, as well as the total number of tracheids, a lower proportion of the variation was accounted for by species $(6.1-27.9 \%)$, with a substantially higher variance related to the differences among individual trees (27.1-37.5\%). The differences between years in the radial number of tracheids explained only $1.5 \%$ of the variance, indicating a small inter-annual variation in tracheid production (Fig. 2).

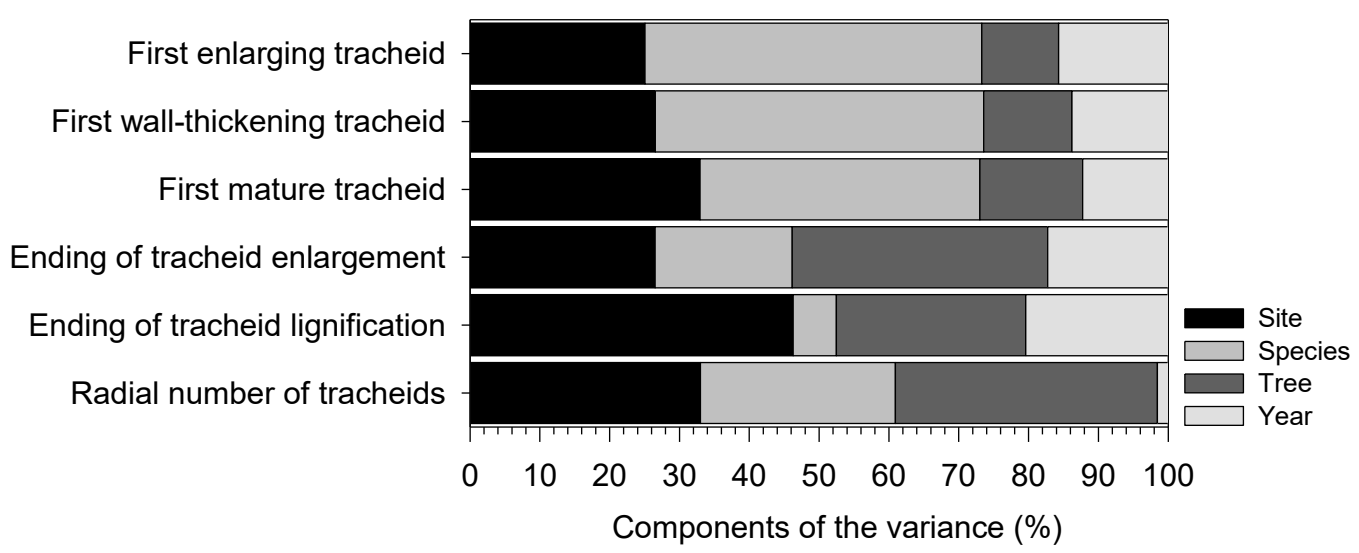

Figure 2: Variance partition of the studied variables (phenological events and cell production) estimated with the Restricted Maximum Likelihood (REML) method.

\section{Model definition and application}

Two divergent patterns were observed between the phenological events and mean annual temperature of the sites (Fig. 3). With increasing temperature, first enlarging, wall-thickening and mature tracheids appeared earlier, and last enlarging and wall-thickening tracheids occurred later. GLM was able to adequately fit the dataset and produced a highly significant 
F-value (Table 2). The $\mathrm{R}^{2}$ indicated that $92 \%$ of the variance was taken into account by the model. A detailed examination of each phenological event demonstrated that all trends were linear within the thermal range analysed, thus the use of GLM was appropriate. The slopes of regressions were statistically different from zero, as well as the interaction term phenology $x$ temperature, indicating that the slopes of regressions changed according to the phenological phases (Table 2). Tests for contrasts revealed that the regressions could be separated in two homogeneous groups. The first one involved the regressions representing spring events: the dates of first enlarging, wall-thickening and mature cells. Between these three regressions, there was no difference in slope $(\mathrm{p}>0.05)$. The second group involved the regressions fitting autumnal events, the ending of cell enlargement and lignification, with slopes that were not statistically different ( $p>0.05)$. Overall, spring and autumnal events had statistically different slopes $(\mathrm{p}<0.0001)$.

Table 2: Results of the Generalized Linear Models (GLM) relating xylem phenology with the mean annual temperature of the sites, with the phenological events and phases being used as covariates, respectively.

\begin{tabular}{ccccccc}
\hline & \multicolumn{3}{c}{ Regressors } & & & Model \\
Source of variation & Type I SS & F-value & P & F-value & P & $\mathrm{R}^{2}$ \\
\hline Phenological event (PE) & 2223393.5 & 3059.7 & $<0.0001$ & & & \\
Mean temperature (MT) & 23467.5 & 129.1 & $<0.0001$ & 1441.0 & $<0.0001$ & 0.92 \\
Interaction PE×MT & 109320.9 & 150.4 & $<0.0001$ & & & \\
\hline
\end{tabular}




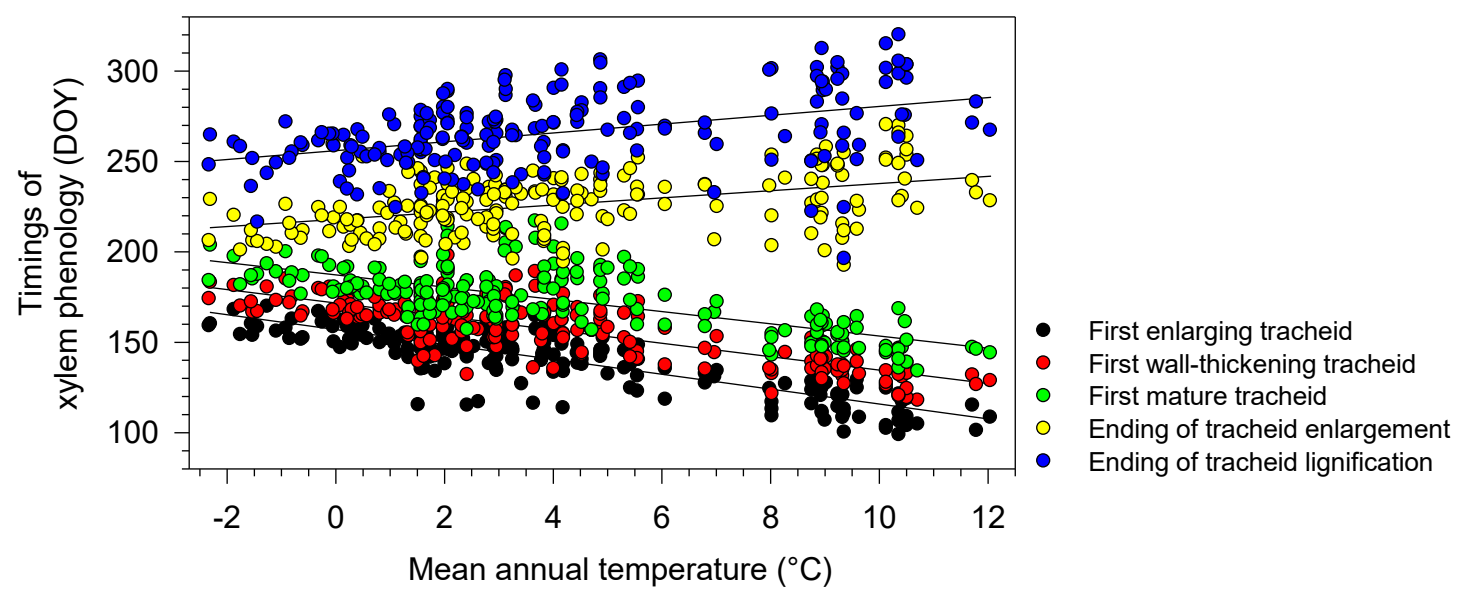

272 Figure 3: Variation in xylem phenology according to the mean annual temperature of the sites. Regression lines represent the predicted values estimated by Generalized Linear Models

274 (GLM). Each differentiation phase is characterized by 204 observations representing the 275 different site $\times$ year $\times$ species combinations.

The residuals of the model were well distributed around zero, and no clear pattern or tendency was observed (Fig. S2). Heteroscedasticity was low, with a variance of residuals constant across the thermal range. The standard deviation of residuals increased gradually during the growing season, with the higher variability observed for autumnal events (Fig. S2). The studentized residuals exceeding the $95 \%$ confidence interval (the range between -2 and 2) were less than $5 \%$ for spring events, but increased to 5.8 and $11.7 \%$ for the ending of cell enlargement and lignification, respectively. The period of wood formation lengthened linearly with the mean annual temperature of the site (Fig. 4). Cell enlargement lasted 48 days at $-2{ }^{\circ} \mathrm{C}$, and 134 days at $12{ }^{\circ} \mathrm{C}$, increasing by 6.1 days ${ }^{\circ} \mathrm{C}^{-1}$. Secondary wall formation lasted from 70.0 to 158.5 days, on average 23.5 days more than cell enlargement. Overall, the period of xylem differentiation (including cell 
enlargement and secondary wall formation) ranged from 83.7 to 178.1 days, and increased by 6.5 days ${ }^{\circ} \mathrm{C}^{-1}$ (Fig. 4). Along the thermal gradient, the slopes of the three regressions representing cell enlargement, secondary wall formation and xylem differentiation were not statistically different $(\mathrm{p}>0.05)$.

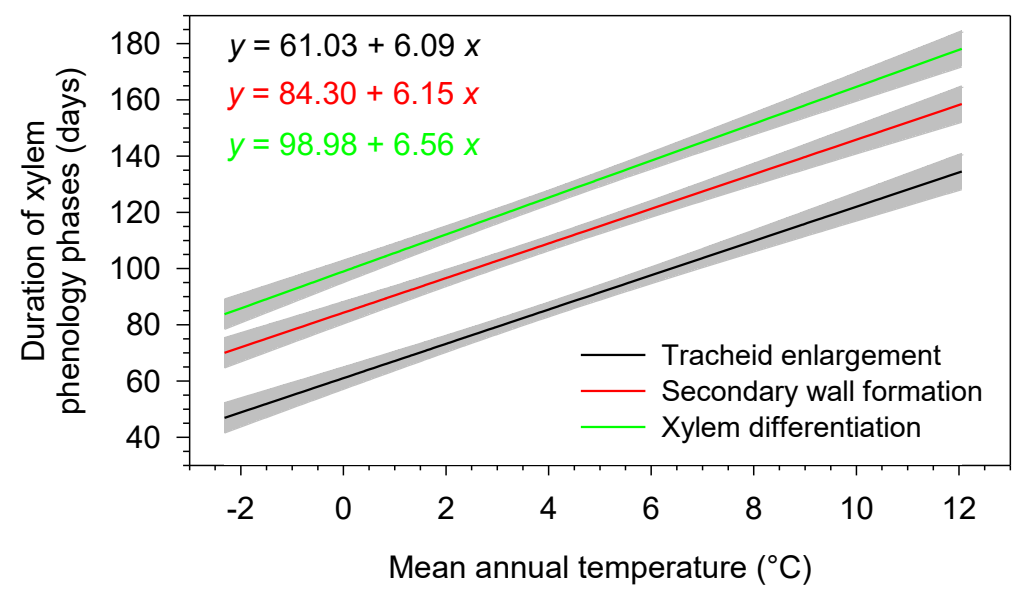

Figure 4: Duration of wood formation according to the mean annual temperature of the sites. Regression lines and grey areas represent the predicted values and their 95\% confidence interval estimated by Generalized Linear Models (GLM), respectively. Xylem differentiation includes the two phases of cell enlargement and secondary wall formation.

\section{Xylem phenology and weekly temperature}

The GLM performed with weekly temperatures produced results similar to the model using annual temperature. However, the variance accounted for changed according to the period of the year considered (Fig. S3). On average, $\mathrm{R}^{2}$ ranged between 88 and $92 \%$. The higher values were concentrated in spring, between the end of March and end of May. After this period, $\mathrm{R}^{2}$ showed an abrupt reduction that lasted until September. The $95 \%$ confidence intervals 
304 calculated by the bootstrap replications demonstrated that spring and summer temperatures

305 produced models with statistically different $\mathrm{R}^{2}$ (Fig. S3). These findings persisted basically

306 unchanged when using averages at daily to monthly scales, although only results with weekly

307 averages are described and reported in this paper. 


\section{Xylem phenology and temperature}

311 There is a long-standing assumption that temperature is one of the main driving forces for

312 plant growth in terrestrial ecosystems, but hemispheric comparisons of the dynamics of xylem

313 formation are still scarce. This study quantitatively demonstrated the thermal constraints to

314 xylem phenology by describing the effects of an interval in the mean annual temperature

315 exceeding $14 \mathrm{~K}$ on the growth period of trees. Unlike the geographical coordinates, the mean

316 annual temperature of the sites represents one, common, and biologically-meaningful

317 variable, allowing this study to describe the variability in xylem phenology of conifer species

318 over three continents and across a wide range of ecosystems. These findings are in general

319 agreement with previous climate-driven models based on temperature, rather than latitude or

320 altitude, which were able to simulate biological phenomena such as treeline position at global

321 scale (Paulsen \& Körner, 2014).

322 Within the range of temperature analyzed, all phases of beginning and ending of wood

323 formation were linearly related to the mean annual temperature. This confirmed the main trends observed along altitudinal (Moser et al., 2010) and latitudinal (Rossi et al., 2014) gradients, although with some differences. In the Swiss Alps, there was a departure from the linear trend for the phases related to the ending of tracheid formation at $1350 \mathrm{~m}$ a.s.1., i.e. the lower altitudinal distribution of European larch (Larix decidua Mill.) (Moser et al., 2010), which may be associated with a reduced availability of water combined with warm conditions in June-July. When plotted with the temperatures of the growing season, Rossi et al. (2014) also found that the relationship between the ending of tracheid enlargement in black spruce [Picea mariana (Mill.) BSP] and the growing season temperature was non-linear because of the disproportionate tracheid production of black spruce in the southernmost part of its 
distribution. Despite the microclimatic effects or local growth dynamics, and regardless of the species considered, this study assessed the linear relationship between temperature and the phenology of xylem growth at wide geographic scale. Thus, it is possible that non-linear trends occur due to multiple environmental effects (i.e. interaction with drought), or under extreme thermal conditions not included in this study. Moreover, the potential changes in sensitivity of trees to the temperature, and long-term adaptation of ecotypes to local climates should be taken into account when interpreting the results of prediction models.

\section{Time window of xylem phenology}

Under the coldest conditions, the duration of cell enlargement was estimated at $46 \pm 5$ (mean $\pm 95 \% \mathrm{CI}$ ) days. The period length is comparable with the minimum duration of cambium activity of six weeks reported for Scots pine (Pinus sylvestris L.) at the Northern treeline (Schmitt et al., 2004). The minimum length of the growing season, defined in literature as the period allowed for the physiological activity of trees, was indicated by measurements and modelling at 90-94 days (Körner \& Paulsen, 2004, Paulsen \& Körner, 2014). In our study, xylem required at least $83 \pm 5$ (mean $\pm 95 \% \mathrm{CI})$ days to complete the maturation of all tracheids produced by cambium. Conifers reactivate some physiological processes such as photosynthesis before cell division in the cambium (Goodine et al., 2008), and at high latitudes the gap between onset of photosynthesis and wood formation can exceed two months (Bäck et al., 2013, Jyske et al., 2014). The shorter period of wood formation compared with photosynthesis may support the hypothesis that tree survival in these coldlimited environments is controlled by sink limitation, i.e. limited demand of carbohydrates for growth rather than carbon assimilation in regions with low mean annual temperatures (Guillemot et al., 2015, Körner, 1998, Leuzinger et al., 2013). However, trees also have large reserves of carbohydrates, which could substantially affect the link between photosynthetic 
production and tracheid formation. Moreover, before the onset of tracheid formation, both the stored and newly assimilated carbon may also be directed to other growing sinks, e.g., shoots, needles and secondary phloem (Gričar et al., 2014, Jyske et al., 2015, Richardson et al., 2015, Schiestl-Aalto et al., 2015).

The sites with the warmest annual temperature were located at the lower elevations in Slovenia, France, Switzerland and Austria. These sites are close to the lower distribution limit of larch, Norway spruce [Picea abies (L.) Karst.] and silver fir (Abies alba Mill.), where cell division lasted up to 134 days and the whole period of wood formation reached 178 days. In the case of reduced summer precipitation, trees in these regions experience water stress during the growing season. The dataset included a dry-mesic site in Austria (called DRY in Table 1), where soil water availability can be a limiting factor for growth during summer (Swidrak et al., 2011). Although growth resumption in this site is still strictly related to spring temperatures (Swidrak et al., 2011), the effects of water constraint appeared clearly at the ending of tracheid differentiation, which occurred earlier than in other sites with similar mean annual temperatures. It is thus likely that the observed linear pattern might not be maintained for warmer annual temperatures because other environmental factors may play a role in affecting the dynamics of xylem phenology and should be taken into account if applying the model under warming scenarios (Delpierre et al., 2015, Gruber et al., 2010).

\section{The process of wood formation}

In longitudinal data, the sequence of phenological events are represented by the changes in traits or attributes in the same individuals over time (Fitzmaurice et al., 2009). Commonly, the sequence of events is serially correlated (Gourieroux \& Jasiak, 2007), as also previously demonstrated for the phases of bud (Rossi \& Bousquet, 2014) and cambium (Rossi et al., 
2012) phenology. A certain phenological phase can only take place after the previous one has occurred. Consequently, delays or advancements of phenological events lead to delay or advancements in the successive events. The correlation between phenological events reveals the interconnection of the differentiation phases and the uniqueness and consistency of the process of wood formation.

The constant interval between the phases of wood formation, which are characterized by the parallel regression lines, is maintained across ecosystems and species, and under the entire range of the thermal conditions analysed (Fig. 3). These findings could suggest two possible hypotheses. First, the rate of tracheid differentiation, here represented by the phases of enlargement and wall thickening of the first and last formed tracheids, is insensitive to temperature. But this hypothesis is counterintuitive and conflicting with previous studies, particularly those related to the process of wall formation (Cuny et al., 2015). Second, the gradual advancement of phenological events with annual temperature most likely reflects the dynamics of spring warming and autumnal cooling across ecosystems. As previously demonstrated (Rossi et al., 2008, Swidrak et al., 2011), beginning and ending of growth arise under similar thermal conditions, which however occur in different moments at latitudes and altitudes on a global scale.

\section{Model interpretation and application}

The underlying physiological mechanisms that drive the activity of cambium and tracheid differentiation are not considered by the regression analysis presented in this paper. Thus, the resulting statistical model remains a simple, albeit hemispheric, description of the changes in xylem phenology with annual temperature of the site, but lacks deterministic tree functioning (Delpierre et al., 2015). Moreover, the annual temperature was chosen as predictor for the 
model, although thermal thresholds or heat sums of shorter time windows, or interaction with other factors such as photoperiod may be considered to depict some specific phenological phases rather better (Körner \& Basler, 2010, Rossi et al., 2008, Schiestl-Aalto et al., 2015, Swidrak et al., 2011). Nevertheless, from a practical point of view, the model represents a tool for demonstrating the annual time window of wood formation in temperate and cold ecosystems around the Northern hemisphere. The model is based on mean annual temperature that is largely accessible or easily computed by spatial interpolation from nearby weather stations, even in remote areas where daily data are generally unavailable.

There is no solid explanation for using the annual mean temperature to describe a biological phenomenon, such as wood formation, that is discontinuous during the year. However, annual mean temperature sufficiently summarized the local climate in cold to temperate regions, and the thermal conditions occurring during wood formation. When reducing the time window of temperatures to shorter periods, April and May resulted in the highest variance accounted for by the model in describing xylem phenology. The models using spring temperatures produced $\mathrm{R}^{2}$ similar to those with annual temperatures. April and May, the two months with the highest relationship with xylem phenology, match the timing of growth resumption, which is associated with the spring increase in temperature (Deslauriers et al., 2008). The pattern of $\mathrm{R}^{2}$ also suggests that spring warming may have the greatest impacts on xylogenesis at global scale. A lower $\mathrm{R}^{2}$ with the temperatures occurring in summer and autumn was observed, as well as a marked increase of the contribution of the factor tree to the total variance of the latest phases of xylem phenology and tracheid production. The increasing dispersion of the residuals during late summer and autumn confirmed this pattern (Fig. S2). Although knowledge on the phenological phases of late summer is still insufficient to depict a common rule (Delpierre et al., 2015), there is general agreement that the ending of xylogenesis should 
427 also be related to other environmental (Swidrak et al., 2011) and endogenous (Rossi et al., 428 2012, Treml et al., 2015) factors.

In temperate and cold regions of the world, trees synchronize the activity of meristems with local climate, concentrating the timings of wood formation within a time window between spring and autumn, when temperature is habitually favorable for growth. This study analyzed an extensive dataset containing intra-annual data on wood formation from sites at mid and high altitudes and latitudes covering an interval of mean annual temperature exceeding $14 \mathrm{~K}$. The timings of wood formation increased linearly according to the local temperature at a rate of 6.5 days ${ }^{\circ} \mathrm{C}^{-1}$. In warmer sites, spring events (first enlarging, wall-thickening and mature tracheids) appeared earlier, while autumnal events (last enlarging and wall-thickening tracheids) occurred later. Under the range of thermal conditions analysed, the phases of onset and ending of tracheid differentiation were separated by constant intervals, demonstrating the uniformity of the wood formation process in conifer species across ecosystems. The spring temperatures were associated with models showing the higher variance accounted for. This demonstrated the importance of the environmental conditions occurring at the time of growth resumption in defining the dynamics of wood formation in temperate and cold regions of the Northern hemisphere. According to the pattern observed in this study and in absence of water stress during the growing season, under warming scenarios xylem phenology might lengthen synchronously in cold biomes regardless of species and sites. 
448 This analysis was performed at the South China Botanical Garden of the Chinese Academy of 449 Sciences (CAS) in Guangzhou during the CAS President's International Fellowship granted 450 to S. Rossi (2015VBB032). The dataset presented in this paper was based on projects funded 451 by 100 Talents Program of the CAS (Y421081001) and National Natural Science Foundation 452 of China (NSFC: 31570584), Austrian Science Fund (FWF P22280-B16; P25643-B16), 453 Consortium de Recherche sur la Forêt Boréale Commerciale, Fonds de Recherche sur la 454 Nature et les Technologies du Québec, Forêt d'enseignement et de recherche Simoncouche, 455 Natural Sciences and Engineering Research Council of Canada, Slovenian Research Agency 456 (young researchers' program to P.P., P4-0015 and P4-0107), MIUR-PRIN 2002 457 (2002075152) and 2005 (2005072877), Swiss National Science Foundation (Projects 458 INTEGRAL and LOTFOR), French National Research Agency (ANR) as part of the 459 "Investissements d'Avenir" program (ANR-11-LABX-0002-01, Lab of Excellence ARBRE), 460 Academy of Finland (Nos. 250299, 257641 and 265504), NSFC (41525001), Grant Agency 461 of Czech Republic (P504/11/P557). The cooperation among authors was supported by the EU 462 COST Action FP1106 STReESS. The authors thank A. Garside for checking the English text. 
Abe H, Funada R, Ohtani J, Fukazawa K (1997) Changes in the arrangement of cellulose microfibrils associated with the cessation of cell expansion in tracheids. Trees, 11, 328-332.

Bäck J, Nikinmaa E, Kulmala L et al. (2013) Processes in living structures. In: Physical and Physiological Forest Ecology. (eds Hari P, Heliövaara K, Kulmala L) pp 534. Springer.

Chmielewski F-M, Rötzer T (2001) Response of tree phenology to climate change across Europe. Agricultural and Forest Meteorology, 108, 101-112.

Chuine I (2010) Why does phenology drive species distribution? Philosophical Transactions of the Royal Society of London, Series B: Biological Sciences, 365, 3149-3160.

Cuny HE, Rathgeber CBK, Frank D et al. (2015) Intra-annual dynamics of woody biomass production in coniferous forests. Nature Plants, 1, 15160.

Cuny HE, Rathgeber CBK, Lebourgeois F, Fortin M, Fournier M (2012) Life strategies in intra-annual dynamics of wood formation: example of three conifer species in a temperate forest in north-east France. Tree Physiology, 32, 612-625.

Delpierre N, Vitasse Y, Chuine I, Guillemot J, Bazot S, Rutishauser T, Rathgeber CBK (2015) Temperate and boreal forest tree phenology: from organ-scale processes to terrestrial ecosystem models. Annals of Forest Science, DOI 10.1007/s13595-015-0477-6.

Deslauriers A, Rossi S, Anfodillo T, Saracino A (2008) Cambium phenology, wood formation and temperature thresholds in two contrasting years at high altitude in Southern Italy. Tree Physiology, 28, 863-871.

Fitzmaurice G, Davidian M, Verbeke G, Molenberghs G (2009) Longitudinal data analysis, Boca Raton, Chapman \& Hall.

Goodine GK, Lavigne MB, Krasowski MJ (2008) Springtime resumption of photosynthesis in balsam fir (Abies balsamea). Tree Physiology, 28, 1069-1076.

Gourieroux C, Jasiak J (2007) The econometrics of individual risk - credit, insurance, and marketing, Princeton, Princeton University Press. 
Gričar J, Čufar K, Oven P, Schmitt U (2005) Differentiation of terminal latewood tracheids in silver fir trees during autumn. Annals of Botany, 95, 959-965.

Gričar J, Prislan P, Gryc V, Vavrčík H, De Luis M, Čufar K (2014) Plastic and locally adapted phenology in cambial seasonality and production of xylem and phloem cells in Picea abies from temperate environments. Tree Physiology, 34, 869-881.

Gruber A, Strobl S, Veit B, Oberhuber W (2010) Impact of drought on the temporal dynamics of wood formation in Pinus sylvestris. Tree Physiology, 30, 490-501.

Guillemot J, Martin-Stpaul NK, Dufrêne E, François C, Soudani K, Ourvival JM, Delpierre N (2015) The dynamic of the annual carbon allocation to wood in European tree species is consistent with a combined source-sink limitation of growth: implications for modelling. Biogeosciences, 12, 2773-2790.

Jyske T, Mäkinen H, Kalliokoski T, Nöjd P (2014) Intra-annual tracheid production of Norway spruce and Scots pine across a latitudinal gradient in Finland. Agricultural and Forest Meteorology, $194,241-254$.

Jyske TM, Suuronen J-P, Pranovich AV, Laakso T, Watanabe U, Kuroda K, Abe H (2015) Seasonal variation in formation, structure, and chemical properties of phloem in Picea abies as studied by novel microtechniques. Planta, DOI 10.1007/s00425-015-2347-8.

Körner C (1998) A re-assessment of high elevation treeline positions and their explanation. Oecologia, 115, 445-459.

Körner C, Basler D (2010) Phenology under global warming. Science, 327, 1461-1462.

Körner C, Paulsen J (2004) A world-wide study of high altitude treeline temperatures. Journal of Biogeography, 31, 713-732.

Leuzinger S, Manusch C, Bugmann H, Wolf A (2013) A sink-limited growth model improves biomass estimation along boreal and alpine tree lines. Global Ecology and Biogeography, 22, 924-932.

Menzel A, Sparks TH, Estrella N et al. (2006) European phenological response to climate change matches the warming pattern. Global Change Biology, 12, 1969-1976. 
Moser L, Fonti P, Buentgen U, Franzen J, Esper J, Luterbacher J, Frank D (2010) Timing and duration of European larch growing season along altitudinal gradients in the Swiss Alps. Tree Physiology, 30, 225-233.

Nord EA, Lynch JP (2009) Plant phenology: a critical controller of soil resource acquisition. Journal of Experimental Biology, 60, 1927-1937.

Paulsen J, Körner C (2014) A climate-based model to predict potential treeline position around the globe. Alpine Botany, 124, 1-12.

Rathgeber CBK, Rossi S, Bontemps J-D (2011) Tree size influences cambial activity in a mature silver fir plantation. Annals of Botany, 108, 429-438.

Richardson AD, Carbone MS, Huggett BA et al. (2015) Distribution and mixing of old and new nonstructural carbon in two temperate trees. New Phytologist, 206, 590-597.

Rossi S, Anfodillo T, Menardi R (2006a) Trephor: a new tool for sampling microcores from tree stems. IAWA Journal, 27, 89-97.

Rossi S, Bousquet J (2014) The bud break process and its variation among local populations of boreal black spruce. Frontiers in Plant Science, 5, 574.

Rossi S, Deslauriers A, Anfodillo T (2006b) Assessment of cambial activity and xylogenesis by microsampling tree species: an example at the Alpine timberline. IAWA Journal, 27, 383-394.

Rossi S, Deslauriers A, Gričar J et al. (2008) Critical temperatures for xylogenesis in conifers of cold climates. Global Ecology and Biogeography, 17, 696-707.

Rossi S, Girard M-J, Morin H (2014) Lengthening of the duration of xylogenesis engenders disproportionate increases in xylem production. Global Change Biology, 20, 2261-2271.

Rossi S, Morin H, Deslauriers A (2012) Causes and correlations in cambium phenology: towards an integrated framework of xylogenesis. Journal of Experimental Botany, 63, 2117-2126.

Rossi S, Morin H, Deslauriers A, Plourde P-Y (2011) Predicting xylem phenology in black spruce under climate warming. Global Change Biology, 17, 614-625. 
541 Schiestl-Aalto P, Kulmala L, Mäkinen H, Nikinmaa E, Mäkelä A (2015) CASSIA - a dynamic model for

542 predicting intra-annual sink demand and inter-annual growth variation in Scots pine. New

$543 \quad$ Phytologist, 206, 647-659.

544 Schmitt U, Jalkanen R, Eckstein D (2004) Cambium dynamics of Pinus sylvestris and Betula spp. in the 545 northern boreal forest in Finland. Silva Fennica, 38, 167-178.

546 Swidrak I, Gruber A, Kofler W, Oberhuber W (2011) Effects of environmental conditions on onset of $547 \quad$ xylem growth in Pinus sylvestris under drought. Tree Physiology, 31, 483-493.

548 Treml V, Kašpar J, Kuželová H, Gryc V (2015) Differences in intra-annual wood formation in Picea 549 abies across the treeline ecotone, Giant Mountains, Czech Republic. Trees, 29, 515-526.

550 Vieira J, Campelo F, Rossi S, Carvalho A, Freitas H, Nabais C (2015) Adjustment capacity of maritime 551 pine cambial activity in drought-prone environments. PLOS ONE, 10:e0126223. 
554 Fig. S1: Location of the study sites.

555 Fig. S2: Studentized residuals of the Generalized Linear Models (GLM) relating the dates of 556 xylem phenology with the mean annual temperature of the sites. Residuals are plotted for each 557 level of the covariate in the model. STD indicates the standard deviation of residuals. The 558 range between -2 and 2 represents the 95\% confidence interval of the Studentized residuals. 559 Each differentiation phase is characterized by 204 observations representing the different site $560 \times$ year $\times$ species combinations.

561 Fig. S3: $\mathrm{R}^{2}$ of the Generalized Linear Models (GLM) relating the dates of xylem phenology 562 with the weekly temperature of the sites. The grey area represents the $95 \%$ confidence interval 563 estimated by 10,000 bootstrapped replications. 